\title{
Commentary: Frailty studies are frail
}

\author{
Alex M. D'Angelo, MD, and \\ Hiroo Takayama, MD, $\mathrm{PhD}$
}

Frailty is an increasingly recognized yet poorly defined concept. It can be generally described as a reduced functional reserve when the body is confronted with acute stress. ${ }^{1-3}$ Such a nebulous definition has led to myriad efforts of quantification, with little consistency. ${ }^{4}$ Frailty is something we, as surgeons, "eyeball."

In this issue of the Journal, Goel and colleagues ${ }^{5}$ analyze a large national administrative database and show that the surgical volume of frail patients, but not the overall surgical volume, is an independent predictor of in-hospital mortality and failure-to-rescue of frail patients undergoing coronary artery bypass grafting or valve surgery. The incidence of postoperative complications was similar across all frail volume quartiles. Notably, minimal correlation was observed between frailty high-volume centers and overall high-volume centers. Together, it is speculated that centers with a higher frailty volume practice have better acute postoperative management and are able to save frail patients. Granular inspection of the data further emphasizes the relevance of this study to our specialty, because frail patients represent $4 \%$ to $6 \%$ of our practice with a high mortality rate of $9 \%$ to $11 \%$

How to introduce a frailty metric in clinical practice, however, is not straightforward. The present study used the Johns Hopkins Adjusted Clinical Groups frailtydefining diagnosis indicator, which is a validated means of analyzing frailty in administrative databases. ${ }^{6}$ The system uses clusters of frailty-defining diagnoses to assign a

\footnotetext{
From the Division of Cardiac, Thoracic, and Vascular Surgery, Department of Surgery, Columbia University Medical Center, New York, NY.

Disclosures: The authors reported no conflicts of interest.

The Journal policy requires editors and reviewers to disclose conflicts of interest and to decline handling or reviewing manuscripts for which they may have a conflict of interest. The editors and reviewers of this article have no conflicts of interest.

Received for publication May 19, 2020; accepted for publication May 20, 2020; available ahead of print June 17, 2020.

Address for reprints: Hiroo Takayama, MD, PhD, Division of Cardiac, Thoracic, and Vascular Surgery, Department of Surgery, Columbia University Medical Center, 177 Fort Washington Ave, New York, NY 10032 (E-mail: ht2225@cumc. columbia.edu).

J Thorac Cardiovasc Surg 2022;163:164-5

$0022-5223 / \$ 36.00$

Copyright (c) 2020 by The American Association for Thoracic Surgery

https://doi.org/10.1016/j.jtcvs.2020.05.073
}

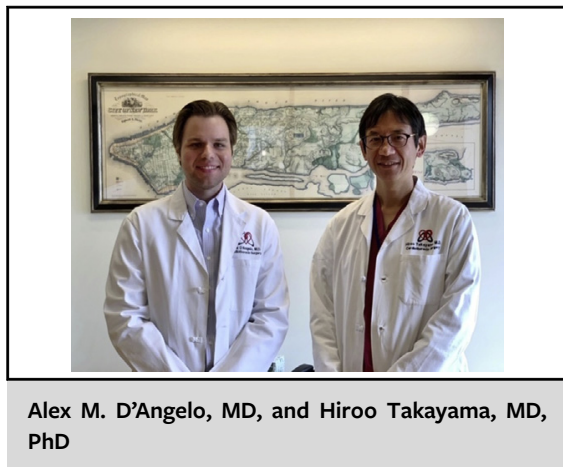

CENTRAL MESSAGE

Lack of a standard definition for

frailty in cardiac surgery makes implementation of the results of studies of frailty difficult and problematic.

binary designation to each patient: frail or not frail. ${ }^{7-9}$ In this study, the most common frailty-defining conditions were rather subjective: malnutrition $(67 \%)$, decubitus ulcer $(16 \%)$, and difficulty walking $(11 \%)$. Furthermore, less common conditions among 10 categories include fecal incontinence and dementia. Surgeons are extremely unlikely to operate on patients with these conditions and frequently are not even consulted, suggesting the lack of relevance of this particular metric for our specialty. A systematic review on this topic showed that objective data, such as stair climbing or gait speed, have been investigated to define frailty in a number of studies, but the definitions remained inconsistent. ${ }^{2}$ Transcatheter aortic valve replacement (TAVR) trials on prohibitive or high surgical risk patients added contemporary knowledge on this topic. Two large studies analyzed objective measures of frailty and found gait speed and low albumin to be independent predictors of mortality after TAVR. ${ }^{10,11}$ The Frailty-AVR study prospectively evaluated patients undergoing TAVR and surgical aortic valve replacement and compared the predictive value of 7 different frailty assessment tools. ${ }^{12}$ They found that although all assessment tools successfully predicted mortality at 1 year, there was significant variability among them. ${ }^{12}$

The present study is another reminder to develop a universal definition of frailty tailored for cardiac surgery and its incorporation into risk assessment models. Until then, clinical practice and research related to frailty may be considered...frail. 


\section{References}

1. Graham A, Brown CH. Frailty, aging, and cardiovascular surgery. Anesth Analg. 2017; 124:1053-60.

2. Sepehri A, Beggs T, Hassan A, Rigatto C, Shaw-Daigle C, Tangri N, et al. The impact of frailty on outcomes after cardiac surgery: a systematic review. J Thorac Cardiovasc Surg. 2014;148:3310-7.

3. Yanagawa B, Graham M, Afilalo J, Hassan A, Arora RC. Frailty as a risk predictor in cardiac surgery: beyond the eyeball test. J Thorac Cardiovasc Surg. 2019;157:1905-9.

4. Yaksic E, Lecky V, Sharnprapai S, Tungkhar T, Cho K, Driver JA, et al. Defining frailty in research abstracts: a systematic review and recommendations for standardization. J Frailty Aging. 2019;8:67-71.

5. Goel N, Iyengar A, Kelly J, Han J, Brown C, Desai N. Volume of frail patients predicts outcome in frail patients after cardiac surgery. $J$ Thorac Cardiovasc Surg. 2022; 163:151-60.e6.

6. Lieberman R, Abrams C, Weiner J. Development and evaluation of the Johns Hopkins University Risk Adjustment Models for Medicare+Choice Plan Payment. Baltimore, MD: Johns Hopkins University; 2003.

7. Neuman HB, Weiss JM, Leverson G, O'Connor ES, Greenblatt DY, Loconte NK, et al. Predictors of short-term postoperative survival after elective

colectomyin colon cancer patients $\geq 80$ years of age. Ann Surg Oncol. 2013 20:1427-35.

8. Nieman CL, Pitman KT, Tufaro AP, Eisele DW, Frick KD, Gourin CG. The effect of frailty on short-term outcomes after head and neck cancer surgery. Laryngoscope. 2018;128:102-10.

9. McIsaac DI, Bryson GL, van Walraven C. Association of frailty and 1-year postoperative mortality following major elective non-cardiac surgery: a population based cohort study. JAMA Surg. 2016;151:538-45.

10. Alfredsson J, Stebbins A, Brennan JM, Matsouaka R, Afilalo J, Peterson ED et al. Gait speed predicts 30-day mortality after transcatheter aortic valve replacement: results from the Society of Thoracic Surgeons/American College of Cardiology transcatheter valve therapy registry. Circulation. 2016;133 1351-9.

11. Hermiller JB, Yakubov SJ, Reardon MJ, Deeb GM, Adams DH, Afilalo J, et al Predicting early and late mortality after transcatheter aortic valve replacement. $J$ Am Coll Cardiol. 2016;68:343-52.

12. Afilalo J, Lauck S, Kim DH, Lefèvre T, Piazza N, Lachapelle K, et al. Frailty in older adults undergoing aortic valve replacement: the FRAILTY-AVR study. $J$ Am Coll Cardiol. 2017;70:689-700. 